\title{
Imatinib-Induced Congestive Heart Failure: A Case Report
}

\section{Ahmed M Shafte}

School of Medicine, University of California at Riverside UCR, Riverside, California, USA

*Corresponding author: Shafter AM, School of Medicine, University of California at Riverside UCR, Riverside, California, USA, Tel: 17734705417; E-mail: dr_shafter@yahoo.com

Received: Feb 22, 2018; Accepted: May 29, 2018; Published: May 31, 2018

Copyright: $\odot 2018$ Shafter AM. This is an open-access article distributed under the terms of the creative commons attribution license, which permits unrestricted use, distribution, and reproduction in any medium, provided the original author and source are credited.

\begin{abstract}
Imatinib has been approved by the FDA as an oral drug for the treatment of Chronic Myeloid Leukemia (CML), gastrointestinal stromal tumors (GISTs) and hyper eosinophilic syndrome. Although imatinib is well tolerated, the incidence of edema and dyspnea are reported to be as high as 66 and $16 \%$, respectively. Imatinib-induced cardiotoxicity is a very uncommon adverse event $<1 \%$. A 53 -year-old male with history of Chronic Myeloid Leukemia $(\mathrm{CML})$ on Imatinib for the past 5 years. He presented with symptoms of exertional dyspnea, poor exercise performance, fatigue, and leg swellings. Chest X-ray revealed cardiomegaly, and pulmonary edema. Electrocardiogram showed normal sinus rhythm, no ischemic changes. Cardiac enzymes were normal. 2D Echocardiogram showed ejection fraction EF of $35 \%$, normal pulmonary systolic pressure, no wall motion abnormality, with normal valvular function. In our case report, we discuss the association between Imatinib use and congestive heart failure, which may need discontinuing the medication and prompt treatment of congestive heart failure.
\end{abstract}

Keywords: Imatinib; Congestive heart failure; Mitochondrial dysfunction; Chronic myeloid leukemia

\section{Introduction}

Imatinib is a revolutionary drug for the treatment of CML by targeting $\mathrm{ABL}$, it efficiently inhibits BCR-ABL+ CML cells, blocks phosphorylation and induces apoptotic cell death [1-17]. Myocardial tissue homeostasis depends largely on mitochondrial function; therefore, an impairment in mitochondrial function will cause cardiac myocyte and endothelial cell death that will ultimately lead to cardiovascular dysfunction. Many chemicals and drugs have been known to alter cardiac mitochondrial function, which can account both for the toxicological and pharmacological properties of these substances [17-24].

\section{Case Presentation}

A 53-year-old male with history of Chronic Myeloid Leukemia (CML) on Imatinib for the past 5 years as maintenance therapy. He presented with symptoms of exertional dyspnea, paroxysmal nocturnal dyspnea, poor exercise performance, fatigue, and leg swellings.

\section{Vital signs}

Blood pressure was $123 / 74 \mathrm{mmHg}$, pulse rate 96 beats/min regular, temperature $98.0^{\circ} \mathrm{F}\left(36.7^{\circ} \mathrm{C}\right)$ Tympanic, respiratory rate $20, \mathrm{SpO}_{2} 94 \%$ on room air. Electrocardiogram showed normal sinus rhythm, no ST-T wave changes. Chest radiograph showed evidence of cardiomegaly, and pulmonary edema. Tow dimensional Echocardiogram showed ejection fraction $\mathrm{EF}$ of $35 \%$, normal pulmonary systolic pressure, otherwise unremarkable.
Labs

WBC 4,600/microL, Hemoglobin Hgb 11.9 g/dl, HCT 34.7\%, MCV $83 \mathrm{fL}$, Platelets 210,000/microL, INR 1.0, PTT 25 s, Glucose $101 \mathrm{mg} / \mathrm{dl}$, Urea $13 \mathrm{mg} / \mathrm{dl}$, S. Creatinine $0.9 \mathrm{mg} / \mathrm{dl}$, GFR $97 \mathrm{~mL} / \mathrm{min} / 1.73 \mathrm{~m}^{2}$, Sodium $133 \mathrm{meq} / \mathrm{L}$, Potassium $4.2 \mathrm{meq} / \mathrm{L}$, S. Troponin I 0.01- 0.041$0.01 \mathrm{ng} / \mathrm{ml}$, BNP 6450 pg/ml. TSH $2.5 \mathrm{mU} / \mathrm{L}$. Ferritin level $150 \mathrm{ng} / \mathrm{mL}$.

ESR, CRP, RF, ANA, complement C3, C4 \& ANCA were normal. Viral serology including Coxsackie virus, Cytomegalovirus, Influenza virus, HIV, Hepatitis C virus, HSV, parvovirus B19 and Ebstein Barr virus serology are all negative. Lyme disease and syphilis serology were negative. Urine drug screen negative for substance abuse.

A diagnosis of acute heart failure was made and imatinib discontinued. He was prescribed comprehensive therapy including oxygen, diuretics and vasodilators according to the ACC/AHA guidelines for the diagnosis and management of heart failure in adults. Patient was sent home on Carvedilol $3.125 \mathrm{mg}$ po BID, Lisinopril $5 \mathrm{mg}$ po daily, and Furosemide $40 \mathrm{mg}$ po daily.

A follow up after 3 months revealed patient's symptoms and signs of heart failure had resolved and findings of biochemical tests, chest Xray film and echocardiogram were all consistent with recovery, where repeat 2D Echocardiogram showed EF of 55\%.

\section{Discussion}

Chronic myeloid leukemia (CML) is a myeloproliferative disorder caused by an acquired mutation of hematopoietic stem cells. This mutation results in a reciprocal translocation between chromosomes 9 and 22 termed the Philadelphia chromosome ( $\mathrm{t}[9 ; 22]$ [q34; q11]) and generates a novel fusion gene, BCR-ABL, which encodes tyrosine kinase. Imatinib mesylate (Gleevec), a small-molecule inhibitor of multiple tyrosine kinases, selectively prevents phosphorylation of BCR$\mathrm{ABL}$ and inhibits downstream signaling and growth of BCR-ABLpositive cells [3-9]. 
Page 2 of 3

Cardiac myocytes consume large amount of adenosine triphosphate (ATP) provided by the mitochondria. Malfunctioning mitochondria are constantly replaced in tightly regulated process to maintain constant ATP production needed for the cardiac muscle. Since cardiac muscle is in a constant energy-consuming contractile state requiring constant ATP supply, and the mitochondria are responsible for the production of ATP, therefore; agents that interfere with the physiological myocardial mitochondrial function are expected to induce depletion of ATP pool leading to myocardial dysfunction.

Imatinib induces mitochondrial dysfunction by interfering with mitochondrial protein import that will negatively affect major mitochondrial metabolic pathways, including mitochondrial DNA synthesis, the Krebs cycle, $\beta$-oxidation, and hem synthesis.

The incidence of imatinib-induced cardiotoxicity increases with age especially with pre-existing cardiovascular disease or renal failure. It ranges from asymptomatic mild LV dysfunction to congestive heart failure. Chemotherapy-induced myocardial injury is monitored by serum biomarkers that are indicative of cardiac injury (serum troponin, creatine kinase $\mathrm{CK}$, myoglobin, fatty acid binding protein 3 (FABP3)) and/or heart failure (B-type natriuretic peptide [BNP]).

BNP is a cardiac neurohormone that is secreted by membrane granules in the cardiac ventricles in response to ventricular volume overload and pressure overload. BNP concentrations are reflective of LV diastolic filling pressures and increased in patients with symptomatic LV dysfunction. In the present case, the concentration of BNP was $6450 \mathrm{pg} / \mathrm{mL}$, reflecting deterioration in cardiac function and Systolic heart failure. After withdrawal of imatinib, not only were the symptoms relieved, but also the BNP concentration decreased significantly, which implied that systolic heart failure in this patient was imatinib-related [7-13].

In summary, imatinib therapy uncommonly causes heart failure $<1 \%$ and mainly occurs in elderly patients with preexisting cardiovascular conditions. Our case demonstrates imatinib induced cardiotoxicity in young patient with no preexisting cardiovascular disease. We recommend that when patients develop symptoms of congestive heart failure, should be monitored closely and treated aggressively with standard medical therapy, including diuretics, and vasodilators. In addition, imatinib mesylate should be discontinued or the dosage reduced [17-21].

\section{Conclusion}

The effect of imatinib on the heart is dose, time, and age dependent. This is clinically important as imatinib treatment is life long and that cardiac damage can be cumulative, that eventually causes congestive heart failure [6-8].

We conclude that imatinib is an uncommon cause of cardiotoxicity with incidence $<1 \%$, and that the cardiovascular adverse events that occur are manageable when recognized and treated. Imatinib remains a potential cardiotoxin, and the cardiac consequences of its long-term use remain unknown.

We recommend treatment of risk factors for cardiovascular disease in imatinib treated patients according the American Heart Association guidelines for the prevention and treatment of heart failure, along with frequent monitoring of signs/symptoms of heart failure.

\section{References}

1. Deininger M, Buchdunger E, Druker BJ (2005) The development of imatinib as a therapeutic agent for chronic myeloid leukemia. Blood 105: 2640-2653.

2. Kantariian HM, O'Brien S, Cortes J, Giles FJ, Rios MB, et al. (2003) Imatinib mesylate therapy improves survival in patients with newly diagnosed Philadelphia chromosome-positive chronic myelogenous leukemia in the chronic phase: Comparison with historic data. Cancer 98: 2636-2642.

3. Kerkelä R, Grazette L, Yacobi R, Iliescu C, Patten R, et al. (2006) Cardiotoxicity of the cancer therapeutic agent imatinib mesylate. Nat Med 12: 908-916.

4. Rainbolt TK, Saunders JM, Wiseman RL (2014) Stress-responsive regulation of mitochondria through the ER unfolded protein response. Trends Endocrinol Metab 25: 528-537.

5. Kerkela R, Grazette L, Yacobi R, Illiescu C, Patten R, et al. (2006) Cardiotoxicity of the cancer therapeutic agent imatinib mesylate. Nat Med 12: 908-916.

6. Talpaz M, Shah NP, Kantarjian H, Donato N, Nicoll J, et al. (2006) Dasatinib in imatinib-resistant philadelphia chromosome-positive leukemias. N Engl J Med 354: 2531-2541.

7. Deming PB, Schafer ZT, Tashker JS, Potts MB, Deshmukh M, et al. (2004) Bcr-Abl-mediated protection from apoptosis downstream of mitochondrial cytochrome c release. Mol Cell Biol 24: 10289-10299.

8. Beininger M, Buchdunger E, Druker BJ (2005) The development of imatinib as a therapeutic agent for chronic myeloid leukemia. Blood 105: 2640-2653.

9. Cohen MH, Williams G, Johnson JR, Duan J, Gobburu J, et al. (2002) Approval summary for imatinib mesylate capsules in the treatment of chronic myelogenous leukemia. Clin Cancer Res 8: 935-942.

10. Atallah E, Durand JB, Kantarjian H, Cortes J (2007) Congestive heart failure is a rare event in patients receiving imatinib therapy. Blood 110: 1233-1237.

11. Hatfield A, Owen S, Pilot PR (2007) In reply to 'Cardiotoxicity of the cancer therapeutic agent imatinib mesylate' Nat Med 13: 15-16.

12. Rosti G, Martinelli G, Baccarani M (2007) In reply to 'Cardiotoxicity of the cancer therapeutic agent imatinib mesylate' Nat Med 13: 15-16.

13. Gambacorti-Passerini C, Tornaghi L, Franceschino A, Piazza R, Corneo G, et al. (2007) In reply to 'Cardiotoxicity of the cancer therapeutic agent imatinib mesylate' Nat Med 13: 13-14.

14. Atallah E, Kantarjian H, Cortes J (2007) In reply to 'Cardiotoxicity of the cancer therapeutic agent imatinib mesylate' Nat Med 13: 14-16.

15. Fernández A, Sanguino A, Peng Z, Crespo A, Ozturk E, et al. (2007) Rational drug redesign to overcome drug resistance in cancer therapy: Imatinib moving target. Cancer Res 67: 4028-4033.

16. Demetri GB (2007) Structural reengineering of imatinib to decrease cardiac risk in cancer therapy. J Clin Invest 117: 3650-3653.

17. Schiffer CA (2007) BCR-ABL tyrosine kinase inhibitors for chronic myelogenous leukemia. N Engl J Med 357: 258-265.

18. Druker BJ, Guilhot F, O'Brien SG, Gathmann I, Kantarjian H, et al. (2006) Five-year follow-up of patients receiving imatinib for chronic myeloid leukemia. N Engl J Med 355: 2408-2417.

19. Hochhaus A, O'Brien SG, Guilhot F, Druker BJ, Branford S, et al. (2009) Six-year follow-up of patients receiving imatinib for the first-line treatment of chronic myeloid leukemia. Leukemia 23: 1054-1061.

20. Tauchi T, Kizaki M, Okamoto S, Tanaka H, Tanimoto M, et al. (2011) Seven-year follow-up of patients receiving imatinib for the treatment of newly diagnosed chronic myelogenous leukemia by the target system. Leuk Res 35: 585-590.

21. Fausel C (2007) Targeted chronic myeloid leukemia therapy: Seeking a cure. Am J Health Syst Pharm 64: 9-15.

22. Turrisi G, Montagnani F, Grotti S, Marinozzi C, Bolognese L, et al. (2010) Congestive heart failure during imatinib mesylate treatment. Int J Cardiol 145: $148-150$. 
Citation: Shafter AM (2018) Imatinib-Induced Congestive Heart Failure: A Case Report. J Cardiovasc Dis Diagn 6: 317 . doi: 10.4172/2329-9517.1000317

Page 3 of 3

23. Verweij J, Casali PG, Kotasek D (2007) Imatinib does not induce cardiac left ventricular failure in gastrointestinal stromal tumors patients: Analysis of EORTC-ISG-AGITG study 62005. Eur J Cancer 43: 974-978.
24. Estabragh ZR, Knight K, Watmough SJ, Lane S, Vinjamuri S, et al. (2011) A prospective evaluation of cardiac function in patients with chronic myeloid leukaemia treated with imatinib. Leuk Res 35: 49-51. 